\title{
Maria Lacerda de Moura e a luta antifascista $(1928-1937)_{1}$
}

Maria Lacerda de Moura and the anti-fascist struggle (1928-1937)

\author{
Claudia Maia2 \\ Patrícia Lessa 3
}

\begin{abstract}
RESUMO
A educadora mineira Maria Lacerda de Moura foi uma anarquista individualista que escreveu sobre o fascismo e as suas consequências mundiais. Questionamos se a sua vivência na comunidade libertária de Guararema (1928-1937) alavancou uma segunda fase de sua obra. Utilizamos, como fonte, os escritos dela no período em que viveu entre libertários.
\end{abstract}

PALAVRAS-CHAVE: Antifascismo. Anarquismo. Maria Lacerda de Moura.

\begin{abstract}
The Minas Gerais educator Maria Lacerda de Moura was an individualist anarchist who wrote about fascism and its worldwide consequences. We questioned whether her experience in the libertarian community of Guararema (1928-1937) leveraged a second phase of her work. We use, as source, her writings in the period she time among libertarians.
\end{abstract}

KEYWORDS: Antifascism. Anarchism. Maria Lacerda de Moura.

$$
* * *
$$

\section{Introdução}

No alvorecer do século XX, a humanidade afundou em duas grandes guerras mundiais, mas, também à época, ergueu-se uma forte corrente internacional conhecida como Anarquismo. O Anarquismo não foi um movimento homogêneo, pois havia divergências nas lutas. Havia os que

\footnotetext{
1 Esta pesquisa contou com apoio financeiro da Fundação de Amparo à Pesquisa de Minas Gerais FAPEMIG.

2 Professora do Programa de Pós-graduação em História da Universidade Estadual de Montes Claros (Unimontes). Email: claudia.maia@unimontes.br. ORCID https://orcid.org/0000-0002-8358-8940

3 Professora Associada C lotada no Departamento de Fundamentos da Educação na Universidade Estadual de Maringá/PR. E-mail: patricialessa13@gmail.com.
} 
lutavam nas trincheiras, lutavam e morriam, em nome da libertação. Um exemplo foram os afiliados à Confederación Nacional del Trabajo (CNT), durante a Revolução Espanhola (1936 - 1939). Os anarcosindicalistas foram às barricadas contra o franquismo, e, com eles, as Mujeres Libres, grupo anarcofeminista, criado por Lucia Sanches Saornil, Amparo Poch y Gascón e Federica Montseny. Elas tiveram contato com o trabalho de Maria Lacerda de Moura, educadora mineira que propunha "guerra à guerra", porém, de modo distinto das libertárias espanholas, a educadora mineira estava ao lado dos anarquistas pacifistas.

Havia anarquistas materialistas e ateus e havia anarquistas espiritualistas. Entendemos que o termo espiritualista é adequado por compreender os grupos e as pessoas que possuem fé, que se vinculam e estudam as manifestações do espírito ou da alma, ou seja, pessoas e grupos que não são materialistas. Miriam Moreira Leite, em seu livro Outra face do feminismo: Maria Lacerda de Moura (1984) utiliza o termo espiritualista para se referir ao refúgio da escritora no Rio de Janeiro, sugerindo que Lacerda tenha dedicado-se aos estudos e às práticas espiritualistas. O que se pode observar, inicialmente, é o afastamento dos escritos de cunho político e o trabalho vinculado à astrologia, que é um estudo dos corpos celestes em suas movimentações e transições relacionados à personalidade e às relações humanas, além, é claro, da volta ao trabalho junto à Ordem Rosa Cruz, da qual havia se afastado desde 1935. A tradição e a cultura Rosa Cruz estão ligadas ao estudo e às práticas místico-filosóficas, sugerindo uma inspiração nos mistérios da Antiguidade egípcia. No Rio, em 1938, ela trabalhou na rádio Mayrink Veiga como astróloga e fez sua última conferência na Ordem Rosa Cruz, 1944, intitulada $O$ silêncio.

Foi um tempo, também, rico no que tange ao alvorecer de crenças e de grupos de estudiosos espiritualistas. Um estudo histórico interessante nesta discussão é a tese de Marcos José Diniz Silva (2015) a qual vale a pena conferir para aprofundamento na questão. Havia muitas frentes internacionais voltadas para o estudo das religiões e das práticas 
espiritualistas. Podemos citar dois exemplos, o Kardecismo na França e a Sociedade Teosófica na Inglaterra. Allan Kardec (1804 - 1869) foi um educador e escritor que deu nome ao Kardecismo ou Espiritismo, doutrina filosófica vinculada ao estudo do Cristianismo. Ele utilizou o pseudônimo para amenizar as perseguições que ocorreram na época do lançamento de seu primeiro livro espírita, O livro dos espíritos, publicado em Paris, dia 04 de abril de 1857. Hippolyte Léon Denizard Rivail, desde então, passou a utilizar o pseudônimo, o que não evitou a perseguição e que seus livros fossem proibidos e queimados em praça pública, não somente na França, mas também em outros países.

A Sociedade Teosófica foi criada na Inglaterra pela escriora Helena Petrovna Blavatsky, nascida na Russia, em 1831. Ela circulou o mundo levando suas ideias e estudando as diferentes religiões, sobretudo Budismo, Cristianismo, Hinduísmo, como também, a ioga e os fenômenos paranormais, atacou o materialismo, o ceticismo e pregou a fraternidade universal. Escreveu várias obras e traduziu para o inglês $A$ voz do silêncio, durante o período em que viveu entre monges tibetanos. A Sociedade Teosófica se expandiu para o mundo e, em 1890, ela criou a sede em Adyan, na Índia; morreu no ano seguinte, em Londres. Sua sucessora, Annie Wood Besant, nasceu em 1847, em Londres, formou-se em química, após a separação com Frank Besant ela mudou para a Índia e adotou o jovem Jiddu Krishnamurti, nascido em Madabapelle, Madras, em 1897. Com outros químicos, ela formou o grupo dos Químicos Ocultos que estudavam o átomo a partir de teorias espiritualistas, em harmonia com as científicas. Foi feminista, vegetariana, antivivisseccionista, lutou pela igualdade de direitos da classe trabalhadora e participou de manifestações e de greves. Com o falecimento de Madame Blavatsky, ela se tornou a presidente da Sociedade Teosófica até a sua morte, na Índia, em 1933 (SILVA, 2015).

O período foi marcado pelo conflito entre religião e ciência, portanto, a criação de grupos kardecista e teosóficos, dentre outros tantos, é a solvência de uma necessidade da época que pedia respostas para além do materialismo 
científico, marcado pelo massacre de vidas humanas e de outras espécies e que serviu para impulsionar a indústria bélica. Maria Lacerda estudou as obras de Kardec e da Sociedade Teosófica. Ela era, portanto, uma anarquista espiritualista. Em consonância com Blavatsky, ela questiona o materialismo científico, sobretudo nas obras Civilização, tronco de escravos (1931) e Fascismo: filho dileto da Igreja e do Capital (1934).

A época foi marcada por muitas outras novidades. Viu surgir ou avançar e propagar algumas tecnologias, tais como o cinema, o telefone, a fotografia, os equipamentos de musculação e retrata as conexões entre as novidades no campo cultural e no científico. A Europa, desse modo, transforma-se em referência mundial em educação, ciência, religião, cultura e arte. O destaque ao belo, ao corpo, ao divertimento são outros pontos que marcam o período. Surgem espaços culturais de entretenimento, tais como os cabarés, as casas de concertos, os cinemas, os teatros, as livrarias, os cafés e os ambientes que eram exclusivos para as exibições físicas e de força. Locais que eram frequentados pela burguesia em alta. Foi um período marcado por corpos glamourizados e com a marcação fixada nas divisões binárias de gênero, por uma estética que circulava pelos espaços públicos e casas de espetáculo ostentando luxo e riqueza. Luxo que contrastava com a miséria e a pobreza que assolava a classe trabalhadora, sobretudo na milionária indústria armamentista, em alta com o avanço nazifascista. Prenúncio das duas grandes guerras que fizeram tremer o chão europeu.

Foi nesse contexto de turbulência, de grandes inovações, de enorme circulação de ideias e de livros e revistas que Lacerda se fez uma escritora e conferencista de reconhecimento internaional. Nascida em Manhuaçu, Minas Gerais, formou-se na escola normalista, trabalhou como educadora e, posteriormente, autodenominou-se "libertária individualista". Sua trajetória iniciou em Minas Gerais, onde se casou ainda jovem e adotou uma menina e um menino. Foi uma ativa educadora, escreveu sobre o feminismo e deu início a sua trajetória como escritora e conferencista. Após a ruptura do casamento, mudou-se para a capital de São Paulo e, logo em seguida, para a comunidade 
rural em Guararema, nesse mesmo Estado. Na comunidade libertária, alavancou sua obra e participou como redatora em importantes jornais da esquerda. Escreveu sobre o vegetarianismo, o amor livre e rompeu com as feministas sufragistas, por considerar que a luta pelo voto era burguesa, que beneficiaria somente uma classe social.

Ao nos debruçarmos sobre a obra de Maria Lacerda de Moura, questionamos a existência de três momentos distintos, ou seja, perguntamos: Há uma mudança no seu pensamento, logo, em sua obra, a partir da sua vivência na comunidade libertária em Guararema (SP), entre 1928 e 1937? É possível verificar mudanças nas suas influências teóricas e de leituras a partir do contato com os chamados "desertores de consciência"? Que novidades ela apresenta em sua obra vivendo entre o/a/s libertária/o/s?

Para pensar as questões apresentadas, daremos destaque ao que nomeamos de o segundo momento de sua obra. Utilizaremos como fontes para análise os seguintes livros escritos no período: Civilização, tronco de escravos (1931); Clero e Estado (1931); Amai e... não vos multipliqueis (1932); Serviço militar obrigatório para mulher? Recuso-me! Denuncio!, (1933); Fascismo: filho dileto da Igreja e do Capital (1934); e, a carta às mães intitulada: Mães brasileiras, mulheres do Brasil!(1935). Partindo desses referentes, dividimos nosso artigo em uma reflexão sobre os contatos que Lacerda teve com os Anarquistas que vieram para o Brasil, fugindo da primeira Guerra Mundial, e, em seguida, afunilamos a discussão para a luta antifascista que ela abraçou na ocasião.

\section{Os laços libertário em Guararema}

Ao escrever sobre o período em que Maria Lacerda de Moura viveu em Guararema, faz-se vultoso o destaque para a seguinte datação: em 1928, aos 41 anos de idade, ela se mudou para Guararema, em São Paulo; em 1937, aos 50 anos, ela foge da repressão do Estado Novo para Barbacena; e, finalmente, em 1938, aos 51 anos, muda-se para a capital do Rio de Janeiro, seu "refúgio 
no espiritualismo" (LEITE, 1984, p. 160). A delimitação desses marcos temporais é um importante elemento para entender a sua obra no contexto da época, caracterizada pela resistência anarquista à onda nazifascista. Luce Fabbri (1908 - 2000) foi uma anarquista italiana que, fugindo do fascismo, veio com a familia se instalar no Uruguai, em 1929, ela nos apresenta uma definição interessante,

O anarquismo é mais um caminho do que um fim, a finalidade é sempre inalcançável, qualquer finalidade, nós a concebemos como inteira, perfeita e como tal não se alcança. Sacrificar a essa finalidade o que a pessoa sente e pensa é suicida, porque na realidade, não se consegue nada, tampouco no momento presente que estamos vivendo, que é o que existe. $\mathrm{O}$ anarquismo é uma forma de sentir o presente em vista de algo, em vista de uma finalidade, quer dizer senti-lo libertariamente, em vista de uma liberdade, pois o perfeito não existe, porém, pode-se ir a ele... não é uma atitude individual, mas social, que interessa à sociedade em seu conjunto, portanto implica organização, ordem, razão... (FABBRI, 1995 apud RAGO, 2007, p. $65)$.

Maria Lacerda estava em consonância com Luce Fabbri, vivendo entre libertário/a/s, porém, diferente de Luce, ela conheceu e se identificou com o anarquismo individualista. Ela sentia e vivia o ar do tempo de modo intenso, tal que sua produção em Guararema foi vasta e potente. Nabylla Fiori de Lima (2016) escreveu sobre o anarquismo individualista na dissertação de mestrado intitulada: Maria Lacerda de Moura na revista Estudios (19301936):

Oposto ao individualismo burguês, o individualismo anarquista vê nos outros indivíduos elementos para a sua complementaridade. Diferentemente do capitalismo que corrói a alteridade, transformando o "outro" em um concorrente, o individualismo libertário entende que a sua liberdade depende da expansão das liberdades dos demais indivíduos da sociedade. Um 
indivíduo totalmente livre é fruto de uma sociedade totalmente livre, de modo que não existe sociedade livre com indivíduos escravizados ou indivíduos livres em uma sociedade autoritária e desigual (LIMA, 2016, p. 69).

Os laços libertários da educadora mineira se fortaleceram quando, em 1926, conheceu o anarquista francês André Néblind, que era um pacifista e lhe apresentou a obra de Han Ryner, escritor francês que propôs o amor plural, ideia, logo em seguida, acolhida pela autora (NEVES, 1980). Dois anos após se conhecerem, ela muda para Guararema, em 1928 e lá permaneceu até 1937 convivendo com Néblind e pessoas de várias nacionalidades que ali viveram ou se hospedaram.

Entre 1930 e 1936, Maria Lacerda foi colaboradora da Revista Estudios, uma importante publicação anarco-individualista da Espanha. A revista, lançada em dezembro de 1928, foi interrompida em 1936. Nessa época contou com a colaboração de libertário/a/s de várias nacionalidades e abordou temas como a sexualidade, a política, a guerra, e, especialmente, foi um instrumento para uma crítica ao nazifascismo. As publicações de Lacerda na referida revista tornaram a autora conhecida na Espanha e proporcionaram contatos e notícias da revolução em curso nas terras flamengas. Nabylla Lima (2016), em sua dissertação, escreve sobre três anarquistas individualistas, são eles: Max Stirner, Han Ryner e Émile Armand. Esse último é o pseudônimo de Armand Juin Ernest Lucien (1872-1963), escritor de mais de vinte livros, colaborador nos jornais anarquistas L'Ére nouvelle (1901-1911), L'Anarchie, L'EnDehors (1922-1939) e L'Unique (1945-1953), escreveu sobre o amor livre, assim como Han Ryner. Sobre a revista Estudios, escreve a autora:

Dentre as publicações de viés anarco-individualista na Espanha, a revista valenciana Estudios foi uma das de maior prestígio. Contava com a contribuição de personalidades das mais diversas. Seu caráter aberto e eclético permitia que as discussões não se encerrassem em posicionamentos 
fechados, caráter ressaltado por Maria Lacerda de Moura ao afirmar o compromisso da revista com o pensamento livre (LIMA, 2016, p. 84).

Margareth Rago (2007, 2012, 2014) escreveu sobre as redes de Maria Lacerda com outras libertárias. Segundo essa autora, em 1934, em Guararema, ela recebeu a visita da amiga argentina Concepción Fernandez que levou um presente de Maria Lacerda para a anarquista ítalo-uruguaia Luce Fabbri. Escreveu Rago: "A dedicatória delicada e afetiva diz: 'Para a querida e grande Luce Fabbri - o coração de Maria Lacerda', 12 - 1934”. As alianças internacionais eram importantes devido à crescente onda nazifascista que avançava e já soprava forte por toda a América Latina. A autora prossegue: “[...] sem dúvida, a escolha não foi gratuita: a aliança na frente de batalha estava solidamente consolidada" (RAGO, 2012, p. 56). Em outra obra, a historiadora registra um achado sobre a solidariedade das Mujeres Libres para com Maria Lacerda quando esta foi presa. As Mujeres Libres formaram um enorme grupo de mulheres chegando a contar com 20.000 associadas, em 1938, durante a Revolução Espanhola. Tinha como órgão de difusão a Revista Mujeres Libres, criada por Lúcia Sánches Saornil, Amparo Poch y Gascón e Mercedes Comaposada. (RAGO, 2007).

Em 1937, a revista Mujeres Libres, número 10, publicava: "Nossa entusiasta e ativa companheira Esperanza Cerrato, secretária da Organização Mujeres Libres, de Valência, comunica que, em Minas Gerais (Brasil), foi levada à prisão a grande lutadora Maria Lacerda de Moura" (RAGO; BIAJOLI, 2007, p. 114). Ela já havia rompido com Bertha Lutz e com as sufragistas por entender que o foco feminista no direito ao voto não atingia todas as mulheres, sobretudo as operárias, as prostitutas e aquelas que viviam à margem da sociedade. Ruptura que pode ser observada na carta em resposta de Lacerda para a $\mathrm{Sr}^{\mathrm{a}}$ Servia F. Vidal, de Buenos Aires, datada de julho de 1930. Na ocasião, a $\mathrm{Sr}^{\mathrm{a}}$ Servia pede a Lacerda para interceder junto a Bertha Lutz para esta ser representante em um grupo que pretendia combater o tráfico de mulheres. Na resposta, a brasileira sugere que não se 
envolverá em questões de mulheres burguesas e reacionárias (MOURA, 1931a).

$\mathrm{Na}$ segunda fase de sua obra, Maria Lacerda faz uma crítica mais virulenta ao feminismo liberal. Enquanto as feministas liberais estavam mais focadas no direito ao voto e ao acesso das mulheres às universidades, Lacerda estava disposta a criticar um dos pilares da burguesia: a família. Ela estava na "contramão dos discursos de autoridades brasileiras científicas, políticas e principalmente jurídicas que criavam a ideia de família como salvaguarda nacional" (MAIA; LESSA, 2015, p 108). Ela pensava o feminismo no contexto das lutas de classe e das lutas operárias, diferente das sufragistas preocupadas com sua inclusão no sistema que as oprimia e excluía: "o feminismo liberal, ao reivindicar, principalmente, o direito ao voto e à instrução, era muito conservador, pois não questionava as estruturas profundas da sociedade burguesa [...]" (RAGO, 2012, p. 65). Essa diferença tem a ver com as relações de gênero e classes, diferença que foi ressaltada no trabalho de Margareth Rago como um marco divisor de águas entre as pioneiras feministas brasileiras liberais e as libertárias, preocupadas com os direitos das trabalhadoras e das mulheres oprimidas em seus lares. $\mathrm{Na}$ matéria "Feminista? Não", publicada no jornal A Manhã do Rio de Janeiro, em dezembro de 1928, Maria Lacerda deixa clara sua posição em relação às filiações feministas, políticas e institucionais:

Não sou feminista, já o declarei. Não sou comunista, não pertenço a nenhum partido político, não pontifico nem sirvo em nenhuma grei. Não exerço nenhum apostolado religioso ou social, não rumino em nenhum rebanho acadêmico ou moralitheista, não bebo a água da vida de nenhuma seita filosófica ou escola científica filológica ou estilizada, clássica ou modernista.

Livre de muleta. Livre de igrejas.

Não sou do Progresso Feminino pró-voto da Sta. Bertha Lutz e nem do bando militarizado e catequista da professora Daltro. 
Voto? _ Nem secreto, nem masculino, nem feminino. (MOURA, 9/dez./1928).

Seus escritos, antes mais direcionados para a educação, agora se ampliam para uma crítica ao capitalismo, ao industrialismo, ao amor e à maternidade por livre escolha e às diferentes formas de opressão das mulheres. Sua aliança anarquista ficou mais forte depois da experiência em Guararema onde a máxima: sem pátria, sem fronteiras, sem família, sem religião e em defesa do livre pensamento pôde ser percebida com mais força em seus livros e nos textos publicados nos jornais nacionais e internacionais.

\section{Guerra à guerra: a luta antifascista na obra lacerdiana}

Lucce Fabbri foi uma anarquista italiana que, juntamente com sua família, fugiu do massacre fascista, vindo se instalar no Uruguai. Sobre o fascismo na Itália e a ascensão dos regimes totalitários na Europa da época escreveu algumas obras, diz ela: "Se a reunião da Praça do Santo Sepulcro em Milão foi algo como o batismo da nova corrente, seu nascimento real é mais dificil de definir, menos localizado no tempo [...]", o fascimo foi observado nas manifestações ultraviolentas de seus adeptos esparramados por toda a Itália. Mais adiante, ela prossegue: "Tratava-se de um ódio tangível, porque estava ligado a situações materiais, e sociólogos podiam medi-lo. Por isso sabemos: a guerra o tornara imenso e o acostumara a pensamentos de morte". (FABBRI, 2019, p. 8 - 9). Da primeira grande guerra até a segunda, o ódio foi o alimento dos nazifascistas.

No contexto das guerras, as famílias numerosas perdiam seus filhos para o serviço militar obrigatório. Foi nesse contexto que Maria Lacerda escreveu Amai e... não vos multipliqueis, publicado em 1932. Nessa obra, ela incitava as mães dos soldados que iam participar da Segunda Guerra Mundial, para que não deixassem que seus filhos se alistassem (LEITE, 2005). Na obra Serviço militar para mulher? Recuso-me! Denuncio!, ela 
afirmou: "a guerra é a bestialidade acordada no homem" (MOURA, 1933, p. 29). Ainda neste livro, conectou as questões da guerra com a superpopulação e a industrialização, afirmando que a indústria bélica se alimenta das guerras e o desenvolvimento da superprodução exige uma grande população de famintos. As mulheres possuíam uma grande missão, não deixar que seus filhos se alistassem no exército, o que, para ela, era muito mais importante do que a luta pelo direito ao voto, que não significava emancipação, pois não atingia todas as mulheres. É nessa perspectiva que ela escreveu:

Já temos uma polícia especializada. Já temos a "Carta del Lavoro" e o Ministério... Policial do Trabalho. Vamos ter o voto obrigatório para homens e mulheres.

Teremos o "serviço militar obrigatório total”, isto é - para ambos os sexos! Recuso-me.

Denuncio.

$[\ldots]$

E a mulher, a tutela milenar desta civilização unissexual, a criadora de vida, a sensibilidade trucidada pela prepotência masculina, protesta contra a organização sistemática dos meios de destruição do trabalho e dos meios de morte da juventude.

E o seu lema, a divisa da mulher para um mundo melhor - não é a violência do vampirismo social erigido em dogma da Pátria ou do bezerro de ouro.

A nossa divisa é um postulado de humanidade:

NEM CARNE FEMININA PARA OS PROSTÍBULOS, NEM CARNE MASCULINA PARA AS BOCAS DOS CANHÕES (MOURA, 1933, p. 19-21).

A missão das mulheres, assim como a dos homens, deveria ser fazer "guerra contra a guerra". Para a autora: "O cão repete o gesto de defesa do lobo. O homem repete o gesto de defesa do troglodita" (MOURA, 1932, apud LEITE, 2005, p. 245). No exercício do seu pensamento, o ser humano deveria 
optar por não matar. Associadas ao pacifismo, as ideias neomalthusianas serviam como argumento para a maternidade consciente.

A Teoria Neomalthusiana foi uma reelaboração das ideias do pensador inglês Thomas Malthus (1736-1834) que, em linhas gerais, preconizou a difusão de medidas governamentais para intensificar o controle do crescimento populacional. Para ele, a relação entre a quantidade de habitantes no mundo era desproporcional à quantidade de alimentos e recursos naturais disponíveis. No período da Segunda Grande Guerra, o mundo passou por uma explosão demográfica, quando a população mundial começou a aumentar de maneira vertiginosa. Para os neomalthusianos, o desenvolvimento da qualidade de vida e da economia de um país ou região perpassava, necessariamente, o controle da população e, para tal empresa, Maria Lacerda propunha a "greve dos ventres": "A suprema resistência ou a resistência heroica da mulher em face da civilização capitalista é a greve dos ventres, é a maternidade consciente e limitada, recusando-se a engendrar a carne para os canhões" (MOURA, 1932, In: LEITE, 2005, p. 251).

Em 1933, os nazistas haviam chegado ao poder na Alemanha e, em 1935, consolidaram uma aliança com a Igreja Católica. O extermínio de judeus, o holocausto perpetrado pelo nazismo foi alcançado graças às redes governamentais internacionais que incluíam estratégias de perseguição, extermínio sistemático em massa e era, cientifica e burocraticamente, organizado. O governo do Brasil ajudou nesse massacre. Genny poderia ter sido uma das vítimas. Genny Gleiser era uma jovem de 17 anos, judia e comunista, nasceu em Bucareste, na Romênia. Seu pai, Motel Gleiser, era um líder sindical em seu país e deixou a terra natal após o suicídio da esposa.

Em 1933, Genny, seu pai e sua irmã Berta, então com oito anos de idade, imigraram para o Brasil. A família se estabeleceu no Rio de Janeiro, local onde seu pai abriu um pequeno comércio. Na capital de São Paulo, no dia 15 de julho de 1935, ela foi presa pelo Departamento de Ordem Política e Social (DEOPS). Naquele dia, ela participava de uma reunião do Congresso da Juventude Proletária Estudantil, no palacete Santa Helena. Era uma 
época de caça ao povo judeu. $\mathrm{O}$ antissemitismo foi muito forte durante a ditadura Vargas. Genny foi presa, torturada e deportada pela ditadura Vargas, em 1935. Na ânsia de encontrá-la, Maria Lacerda de Moura escreveu uma belíssima e emocionante carta, no dia 19 de setembro de 1935. Sem saber que o destino da jovem já estava selado, escreveu:

Mães brasileiras, mulheres do Brasil! [...]

Geny Gleiser é uma operaria. Geny é dessa classe explorada, cujos expoentes de caráter, de convicções, de coragem, são trucidados lá pelas matas da Tijuca, apodrecem no fundo dos cárceres ou nos porões dos navios, sem que os seus amigos ou camaradas consigam arrebata-la ao se martírio. Mas, os moços bonitos, da fina e alta sociedade, os vossos filhos, filhos de altas patentes militares, de políticos, de capitalistas, de diplomatas, os filhos de papai, esses têm o direito (de classe...) de gritar alto as suas conviç̧ões de comunistas ou integralistas, vestem a camisa verde do fascismo nacional, sem que, por isso, a polícia política os incomode (MOURA, 2007, p. 19).

Maria Lacerda via, nas mães brasileiras, um potencial de luta, pois acreditava na maternidade espiritual, aquela que toca os corações das mulheres ante a violência infringida às crianças e aos jovens. Nesse sentido, ela escreveu:

A Itália de Mussolini, na sua fúria de rapinagem, acaba de decretar a "mobilização de experiência" de 10 milhões, incluídas as mulheres e as crianças!

Cuidado com as vossas filhas!... Hoje é Geny Gleiser a encarcerada incomunicável, amanhã será qualquer bonequinha de salão, dessas que fazem a delícia de vossas vidas de mães burguesas, indiferentes às desgraças do mundo inteiro. [...]

Esse anseio de Liberdade palpita angustioso no coração da juventude moderna (MOURA, 2007, p. 20-21). 
O caso da prisão ilegal de Genny Gleiser, uma jovem de 17 anos, foi um dos tópicos que marcaram a escrita e a luta da Maria Lacerda contra o fascismo. Em Clero e Estado, um texto fruto de uma palestra de Maria na Liga Anti-clerical do Rio de Janeiro, ela questiona: "Há quanto tempo a Igreja esperava Mussolini?" (MOURA, 1931b, p. 9). Na mesma palestra ela diz: "Somos a ponte entre duas épocas. Somos o marco entre duas civilizações. O silêncio, agora, é a conivência" (MOURA, 1931b, p. 5). Ela não se calou. Em Civilização: tronco de escravos (1931a), escreveu sobre a indústria bélica e o colaboracionismo para com os nazifascistas. Para ela, o mal não estava na falta, mas sim no excesso de produção das indústrias, em expansão. Havia terra e pão para todas as bocas, mas a ganância da elite burguesa, associada à ciência e ao poder político, geravam o excesso (MOURA, 1931a). Ela inicia a obra relatando o caso de Voronoff, um cientista que vendia a proposta de rejuvenescimento por meio de enxertos das glândulas de macacos em humanos. Nesse tópico, ela denuncia a tortura do viviccionismo e dos usos de outras espécies a favor do consumismo das realizações cientificas em voga.

Na obra Fascismo: filho dileto da Igreja e do Capital (1934) ela inicia escrevendo sobre a colaboração da igreja com Hitler e Mussolini, faz um apanhado histórico da colaboração da elite Católica com os governos, no período medieval. E, por fim, une-se às propostas pacifistas, cita as obras de Madame Blavatsky Isis sem véu (1877) e A Doutrina Secreta (1888) como provas do grande massacre perpetrado pela igreja contra diferentes crenças e contra as ciências ocultas, à fim de se manter no poder pela hegemonia supersticiosa e impositiva. Maria Lacerda encontrou respaldo na obra da criadora da Sociedade Teosófica, pois ambas entendiam a instituição religiosa cristã como um local de disputa de poder, na qual o foco na espiritualidade havia se perdido graças a suas conexões com os poderes políticos e econômicos. Para ambas, o Catolicismo havia perdido o elo com as palavras de Jesus Cristo, pois estava muito ocupado com o poder e o dinheiro. Sua luta pela paz e por uma vida estoica pode ser lida ao final de Civilização: tronco de escravos quando ela escreve: "Só a volta à natureza, a serenidade simples do campo, a 
sobriedade, nos dão ideia de que é possivel fugir da loucura coletiva da civilização industrial e sentir a alegria de viver" (MOURA, 1931a, p. 233).

\section{Considerações finais}

Maria Lacerda de Moura escreveu seu primeiro livro Em torno da educação, em 1918. Perguntamo-nos por que escrever sobre uma obra centenária? Que novidades a feminista libertária pode nos oferecer? Pensamos que a obra lacerdiana é relevante no contexto de retomada das discussões fascistas. Como vimos, a obra escrita no período que ela viveu na comunidade libertária de Guararema é vasta. Assim, fizemos um pequeno recorte, destacando alguns textos, especialmente o momento em que ela entra em dialogo com o movimento anarquista internacional.

Em Guararema, ela escreveu sobre a guerra e suas consequências mundiais, sobre a corrida armamentista e as suas vítimas, sejam elas as que morriam nas guerras ou sejam as que trabalhavam nas indústrias, durante longas jornadas e sem nenhuma segurança contra os acidentes químicos ou mecânicos. A autora foi propositiva ao mostrar outros caminhos, seja no combante à guerra, seja na procura por uma fraternidade universal. Hoje, com a crescente onda de incitação ao ódio que divide a população brasileira, é imprescindível retomarmos escritora/e/s que lutaram e vivenciaram processos de libertação. A retomada dos textos sobre as lutas antifascistas dos anos 1930 é urgente! Maria Lacerda de Moura foi uma ousada libertária que escreveu sobre tópicos ainda vistos como tabu: o aborto, o amor livre, o sexo fora do casamento e, sobretudo, sobre o pensamento e a ação anarquista na ditadura Vargas. Afrontou os ditadores, analisou a relação entre o Estado e a instituição religiosa para pensar a condição das mulheres. Apontou caminhos para a libertação dessas mulheres, para a libertação animal e para a libertação humana fora dos esquemas tradicionais.

Ela faleceu no dia 20 de março de 1945, na cidade do Rio de Janeiro, aos 57 anos. Teve uma vida curta, mas muito intensa, que precisa ser 
lembrada, contada, reverberada. Sua experiência em Guararema pode nos dizer muito sobre a necessidade de economias solidárias, sobre o vegetarianismo e a ética com relação às outras espécies, sobre as comunidades libertárias, sobre a vida no campo, sobre o meio ambiente, sobre a produção e o consumo de alimentos orgânicos, sobretudo nestes tempos de envenenamento dos nossos corpos, do nosso solo, das nossas águas e, por que não dizer, da vida planetária. Na comunidade rural autogestionária, em 1937, ela e a/o/s companheira/o/s foram atacada/o/s pela polícia política; por isso, mudou-se para o Rio de Janeiro, em 1938, após uma rápida passagem por Minas. Como uma guerreira incansável, Maria Lacerda, iniciou uma nova fase em sua vida, realizando muitas conferências e escrevendo sobre outros temas. Seus diversos escritos estão espalhados por aí em jornais, livros, livretos, revistas, etc., à espera de outra/es leitora/es e de novas pesquisas.

\section{Referências}

FABBRI, Luce. Fascismo: definição e história. Tradução Fernanda Grigolin, Rodrigo Millán e Aquela Mulher do Canto Esquerdo do Quarto; prefácios Elena Schembri e Geraldo Garay; epílogos Margareth Rago, Ivanna Margarucci e Thiago Lemos; notas Dario Marroche et al. São Paulo: Tenda de Livros: Publication Studio São Paulo, 2019; Montevideo: Microutopías, 2019.

LEITE, Miriam Lifchitz Moreira. Maria Lacerda de Moura: uma feminista utópica. Florianópolis: Editora Mulheres, 2005.

Outra face do feminismo: Maria Lacerda de Moura. São Paulo: Atica, 1984.

LIMA, Nabylla Fiori de. Maria Lacerda de Moura na revista Estudios (1930-1936): anarquismo individualista e filosofia da natureza. 2016. 167f. Dissertação (Mestrado na linha Tecnologia do Trabalho) - Programa de Pós-Graduação em Tecnologia, Universidade Federal Tecnologica do Paraná, Curitiba, 2016. Disponível em: 
<http://repositorio.utfpr.edu.br/jspui/bitstream/1/1993/1/CT_PPGTE_M_Lima\%2C \%20Nabylla\%20Fiori_2016.pdf>. Acesso em: 08 nov. 2019.

MAIA, Claudia; LESSA, Patrícia. Maria Lacerda de Moura: crítica à família burguesa e à exploração feminina. MAIA, Claudia; PUGA, Vera. História das Mulheres e do Gênero em Minas Gerais. Ilha de Santa Catarina: Editora Mulheres, 2015, p. 97-121.

MOURA, Maria Lacerda. Feminista? - Não. A Manhã. Rio de Janeiro, 09. Dez.1928.

MOURA, Maria Lacerda. Civilização, tronco de escravos. Rio de Janeiro: Civilização Brasileira, 1931a.

. Clero e Estado. Publicação da Liga Anti-Clerical: Rio de Janeiro, 1931 b.

1934

Fascismo: filho dileto da Igreja e do Capital. São Paulo: Editora Paulista, 1933. Serviço militar obrigatório para mulher? Recuso-me! Denuncio!. 3. Ed, S/C: Opúsculo Libertário, 1999.

Amai e... não vos multipliqueis. 1932. In: LEITE, M. L. M. (Org.) Maria Lacerda de Moura: uma feminista utópica. Florianópolis: Ed. Mulheres; Santa Cruz do Sul: Edunisc, 2005, p. 202 - 270.

. Mães brasileiras, mulheres do Brasil! 19 de setembro de 1935. In:

RODRIGUES, Edgar. Mulheres e anarquia. Rio de Janeiro: Achiamé, 2007, p. 1923.

NEVES, Roberto das. Entre colunas. Rio de Janeiro: Germinal, 1980.

RAGO, Margareth. Entre o anarquismo e o feminismo: Maria Lacerda de Moura e Luce Fabbri. Verve Revista do Núcleo de Sociabilidade Libertária Pepgcs. Puc/SP, v.21, p. 54-77, São Paulo, 2012.

Do cabaré ao lar: a utopia da cidade disciplinar e a resistência anarquista, Brasil 1890-1930. Rio de Janeiro: Paz e Terra, 2014. 
RAGO, Margareth; BIAJOLI, Maria Clara Pivato. Mujeres Libres da Espanha: documentos da revolução espanhola. Rio de Janeiro: Achiamé, 2007.

SILVA, Marcos José Diniz. Maçonaria, Teosofia e Esperanto: afinidades espiritualistas em redes intelectuais no Ceará dos anos 1920. Locus: Revista de História, Juíz de Fora, v.20, n. 2, p. 191-211, 2015.

Recebido em outubro de 2019.

Aprovado em dezembro 2019. 